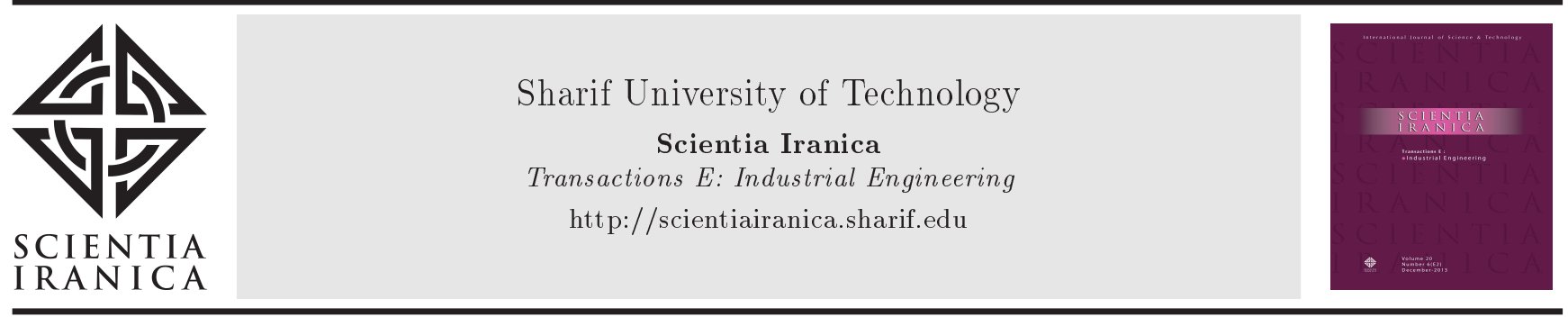

\title{
Measuring congestion in data envelopment analysis without solving any models
}

\author{
S. Navidi, M. Rostamy-Malkhalifeh*, and F. Hosseinzadeh Lotfi \\ Department of Mathematics, Science and Research Branch, Islamic Azad University, Tehran, Iran.
}

Received 9 April 2019; received in revised form 9 October 2019; accepted 28 December 2019

\section{KEYWORDS}

Data envelopment

analysis;

Congestion;

Decision making unit;

Efficient;

Production possibility set.

\begin{abstract}
One of the important topics in data envelopment analysis is congestion. Many scholars conduct research in this field and present their methods. In most cases, we must solve many models or use them for special purposes, such as negative data, integer data, different production possibility set, and so on. Here, we present our method, which can measure the congestion without solving a model. It can be used for different production possibility set (different technology) such as $T_{N e w}$ and FDH, and different data like negative data and integer data. In addition, we can distinguish between strong and weak congestion of the Decision-Making Unit (DMU). Furthermore, each DMU has congestion, efficiency, and inefficiency, and we can use this method to measure them. Finally, we present some numerical examples of our method, and we compare our method with other methods, and then we display the results in a table.
\end{abstract}

(C) 2021 Sharif University of Technology. All rights reserved.

\section{Introduction}

The Data Envelopment Analysis (DEA) model is used to estimate the performance of the Decision-Making Unit (DMU) by measuring relative efficiency. Charnes et al. [1] proposed the CCR model and Banker et al. [2] proposed the BCC model. Although other researchers proposed many models, these two models are the most important and practical models.

To use the DEA model, inputs and outputs must be defined for the DMU. Congestion occurs when the increase of one/more inputs leads to the decrease of one/more outputs without improving any other inputs or outputs $[3,4]$. Färe and Grosskopf $[5,6]$ proposed a

\footnotetext{
*. Corresponding author.

E-mail addresses: s_navidi@yahoo.com (S. Navidi); mohsen_rostamy@yahoo.com (M. Rostamy-Malkhalifeh); farhad@hosseinzadeh.ir (F. Hosseinzadeh Lotfi)
}

doi: $10.24200 /$ sci.2019.53160.3092 method to identify the input factors which create the congestion. Brockett et al. [7] believed that congestion of DMU depends on its inputs. Some researchers have tried to express the method to measure congestion by solving fewer models [8-10].

Other researchers have proposed their models for measuring congestion in different fields. Zare-Haghighi et al. [11] used the ideal and non-ideal output to measure congestion. Mollaeian and Rostamy Malkhalifeh [12] focused on congestion in the supply chain. Abbasi et al. [13] measured the congestion in Free Disposal Hull (FD).

Congestion is used in different fields such as economy, industry, and energy. These fields have been carefully studied by Sueyoshi and Goto $[14,15]$. They proposed their method by describing desirable and undesirable congestion.

Ebrahimzade Adimi et al. [16] proposed a method to find the congestion hyperplane. Khoveyni et al. [17] proposed their method for identifying congestion with negative data. Wang et al. [18] presented a new 
definition of congestion. Sole-Ribalta et al. [19] studied the congestion of multiplexed networks. Another topic of interest to researchers related to congestion is energy efficiency [20-22].

The rest of this paper is organized as follows: In Section 2, we review some other works in the congestion field. Our proposed method is described in Section 3. The experimental testing of our proposed method is described in Section 4. The conclusion is presented in Section 5 .

\section{Background}

In this section, we briefly define some models for measuring congestion. Assume that, the number of DMUs, inputs, and outputs are $n, m$, and $s$. The vectors $x_{j}=\left(x_{1 j}, \ldots, x_{m j}\right)^{T}$ and $y_{j}=\left(y_{1 j}, \ldots, y_{m j}\right)^{T}$ are the input and output values of $D M U_{j}, j=1, \ldots, n$, respectively. Cooper et al. [8] proposed this model:

$$
\operatorname{Max} \varphi+\varepsilon\left(\sum_{r=1}^{s} s_{r}^{+}-\varepsilon \sum_{i=1}^{m} s_{i}^{-c}\right)
$$

s.t.:

$$
\begin{aligned}
& \sum_{j=1}^{n} \lambda_{j} x_{i j}+s_{i o}^{-c}=x_{i o}, \quad i=1,2, \ldots, m, \\
& \sum_{j=1}^{n} \lambda_{j} y_{r j}-s_{r o}^{+}=\varphi_{o} y_{r o}, \quad r=1,2, \ldots, s, \\
& \sum_{j=1}^{n} \lambda_{j}=1, \\
& 0 \leq \lambda_{j}, s_{r o}^{+}, s_{i o}^{-c}, \quad j=1,2, \ldots, n, \\
& i=1,2, \ldots, m, \quad r=1,2, \ldots, s .
\end{aligned}
$$

$\varepsilon>0$ is a non-Archimedean element smaller than any positive real number. In fact, it is only theoretically used to display a two-step model in one model. For more details refer to [7].

The optimal solution of Eq. (1) is $\left(\varphi^{*}, \lambda^{*}\right.$, $\left.s^{+^{*}}, s^{-c^{*}}\right)$. We will have congestion if and only if at least one of the following two conditions is satisfied:

I. $\varphi^{*}>1$ and there is at least one $s_{i}^{-c^{*}}>0(i=$ $1,2, \ldots, m)$;

II. There are at least one $s_{r}^{+^{*}}>0(r=1,2, \ldots, s)$ and one $s_{i}^{-c^{*}}>0(i=1,2, \ldots, m)$.

Noura et al. [10] proposed their method as follow: First, the output-oriented BCC model is solved [2]:
$\operatorname{Max} \varphi+\varepsilon\left(\sum_{r=1}^{s} s_{r}^{+}+\sum_{i=1}^{m} s_{i}^{-}\right)$

s.t.:

$\sum_{j=1}^{n} \lambda_{j} x_{i j}+s_{i o}^{-}=x_{i o}, \quad i=1,2, \ldots, m$,

$\sum_{j=1}^{n} \lambda_{j} y_{r j}-s_{r o}^{+}=\varphi_{o} y_{r o}, \quad r=1,2, \ldots, s$,

$\sum_{j=1}^{n} \lambda_{j}=1$

$0 \leq \lambda_{j}, s_{\text {ro }}^{+}, s_{i o}^{-}, \quad j=1,2, \ldots, n$,

$i=1,2, \ldots, m, \quad r=1,2, \ldots, s$.

The optimal solution of Eq. (2) is $\left(\varphi^{*}, \lambda^{*}, s^{+^{*}}, s^{{ }^{*}}\right)$. Then set $E$ is defined as follow:

$$
E=\left\{j \mid \varphi_{j}^{*}=1\right\}, \quad \varphi_{j}^{*} \text { is } \varphi^{*} \text { for } D M U_{j} \text {. }
$$

A DMU in set $E$ which has the highest amounts of $i$ th input component compared with other DMUs is selected.

$$
\begin{aligned}
& \exists(t \in E) ; \quad \forall(j \in E) \Rightarrow x_{i t} \geq x_{i j} ; \\
& x_{i t}=x_{i}^{*}, \quad i=1, \ldots, m .
\end{aligned}
$$

We will have congestion if and only if at least one of the following two conditions is satisfied:

I. $\varphi^{*}>1$ and there is at least one $x_{i o}>x_{i}^{*}(i=$ $1,2, \ldots, m)$;

II. There are at least one $s_{r}^{+^{*}}>0(r=1,2, \ldots, s)$ and one $x_{i o}>x_{i}^{*}(i=1,2, \ldots, m)$.

Khoveyni et al. [17] proposed their method for negative data based on the slack-based DEA approach. In their method it is assumed that $D M U_{j}, j=$ $1, \ldots, n$, is $P_{\text {Convex }}$ efficient. Khoveyni et al.'s method is presented as follows:

$\operatorname{Max} \sum_{r=1}^{s} s_{r}^{+}$

s.t.:

$\sum_{j=1}^{n} \lambda_{j} x_{i j}+s_{i}^{-}=x_{i o}, \quad i=1,2, \ldots, m$,

$\sum_{j=1}^{n} \lambda_{j} y_{r j}-s_{r}^{+}=y_{r o}, \quad r=1,2, \ldots, s$,

$\sum_{j=1}^{n} \lambda_{j}=1, \quad 0 \leq \lambda_{j}, \quad j=1,2, \ldots, n$, 


$$
\begin{aligned}
& 0 \leq s_{i}^{-}, \quad i=1,2, \ldots, m, \\
& \varepsilon \leq s_{r}^{+}, \quad r=1,2, \ldots, s .
\end{aligned}
$$

By solving Eq. (5), we have two cases:

1. If Model (5) is feasible, then $D M U_{o}$ has congestion. To determine the type of congestion (strong or weak), Khoveyni et al. [17] proposed the following model:

$$
\begin{aligned}
& \operatorname{Max} \sum_{i=1}^{m} s_{i}^{-}, \\
& \text {s.t.: } \\
& \sum_{j=1}^{n} \lambda_{j} x_{i j}+s_{i}^{-}=x_{i o}, \quad i=1,2, \ldots, m, \\
& \sum_{j=1}^{n} \lambda_{j} y_{r j}=y_{r o}+s_{r}{ }^{*}, \quad r=1,2, \ldots, s, \\
& \sum_{j=1}^{n} \lambda_{j}=1, \quad 0 \leq \lambda_{j}, \quad j=1,2, \ldots, n, \\
& \varepsilon \leq s_{i}^{-}, \quad i=1,2, \ldots, m,
\end{aligned}
$$

where $s_{r}{ }^{{ }^{*}}(r=1,2, \ldots, s)$ are the optimal solutions obtained from Model (5), which are fixed in Model (6).

1.1 If Model (6) is feasible, then $D M U_{o}$ has strong congestion;

1.2 If Model (6) is infeasible, then $D M U_{o}$ has weak congestion.

2. If Model (5) is infeasible, then $D M U_{o}$ does not have congestion. Then Khoveyni et al. [17] proposed the following model:

$$
\begin{aligned}
& \operatorname{Max} z_{k}=\sum_{r=1}^{s} s_{r}^{+}, \\
& \text {s.t.: } \\
& \sum_{j=1}^{n} \lambda_{j} x_{i j}+s_{i}^{-}=x_{i o}, \quad i=1,2, \ldots, m, \\
& \sum_{j=1}^{n} \lambda_{j} y_{r j}-s_{r}^{+}=y_{r o}, \quad r=1,2, \ldots, s, \\
& \sum_{j=1}^{n} \lambda_{j}=1, \quad 0 \leq \lambda_{j}, \quad j=1,2, \ldots, n, \\
& 0 \leq s_{i}^{-}, \quad i=1,2, \ldots, m, \\
& 0 \leq s_{r}^{+}, \quad r=1,2, \ldots, s .
\end{aligned}
$$

The optimal solution of Eq. (7) is $\left(Z_{k}^{*}, \lambda^{*}, s^{+^{*}}, s^{-^{*}}\right)$.

2.1 If $z_{k}^{*}>0$, then $D M U_{o}$ has weak congestion;

2.2 If $z_{k}^{*}=0$, then $D M U_{o}$ doesn't have weak congestion.

Abbasi et al. [13] proposed $F D H^{-1}$ output additive model to estimate the congestion in the FDH model. At first, consider the following model:

$$
\begin{aligned}
& \operatorname{Max} Z_{F D H}=\sum_{r=1}^{s} s_{r}^{+}, \\
& \text {s.t.: } \\
& \sum_{j=1}^{n} \lambda_{j} x_{i j} \leq x_{i o}, \quad i=1,2, \ldots, m, \\
& \sum_{j=1}^{n} \lambda_{j} y_{r j}-s_{r}^{+}=y_{r o}, \quad r=1,2, \ldots, s, \\
& \sum_{j=1}^{n} \lambda_{j}=1, \quad \lambda_{j} \in\{0,1\}, \quad j=1,2, \ldots, n, \\
& 0 \leq s_{r}^{+}, \quad r=1,2, \ldots, s .
\end{aligned}
$$

In Model (8), if $Z_{F D H}=0$ then $D M U_{o}$ is FDH output efficient. Then consider the following model:

$\operatorname{Max} Z_{F D H^{-1}}=\sum_{r=1}^{s} s_{r}^{+}$,

s.t.:

$$
\begin{aligned}
& \sum_{j=1}^{n} \lambda_{j} x_{i j} \geq x_{i o}, \quad i=1,2, \ldots, m, \\
& \sum_{j=1}^{n} \lambda_{j} y_{r j}-s_{r}^{+}=y_{r o}, \quad r=1,2, \ldots, s, \\
& \sum_{j=1}^{n} \lambda_{j}=1, \quad \lambda_{j} \in\{0,1\}, \quad j=1,2, \ldots, n, \\
& 0 \leq s_{r}^{+}, \quad r=1,2, \ldots, s .
\end{aligned}
$$

In Model (9), if $Z_{F D H^{-1}}=0$ then $D M U_{o}$ is $F D H^{-1}$ output efficient. $D M U_{o}=\left(x_{o}, y_{o}\right)$ has congestion if there is $D M U_{k}=\left(x_{k}, y_{k}\right)$ and; $x_{k} \leq x_{o}, x_{k} \neq x_{o}$ and $y_{k} \geq y_{o}, y_{k} \neq y_{o}$. If $x_{k}<x_{o}$ and $y_{k}>y_{o}$ then $D M U_{o}$ has strong congestion.

Abbasi et al. [13] pointed out that $D M U_{o}$ has congestion if and only if $D M U_{o}$ is $F D H^{-1}$ output efficient and is not FDH output efficient. Therefore, the following steps must be accomplished:

1. Solve Model (9), the optimal solution of Model (9) is $\left(\lambda^{*}, s^{+^{*}}\right)$. Let $\widehat{y_{o}}=y_{o}+s^{+^{*}}$. It is obvious that $\left(x_{o}, \widehat{y}_{o}\right)$ is $F D H^{-1}$ output efficient; 
2. Solve Model $(8)$ to find $\left(x_{o}, \widehat{y_{0}}\right)$;

3. If $Z_{F D H}>0$ then $D M U_{o}$ has congestion.

\section{Proposed method}

Based on the Noura et al. [10] method, we propose a method to measure congestion without solving any model.

Assume that, the number of DMUs, inputs, and outputs are $n, m$, and $s$. The vectors $x_{j}=$ $\left(x_{1 j}, \ldots, x_{m j}\right)^{T}$ and $y_{j}=\left(y_{1 j}, \ldots, y_{m j}\right)^{T}$ are the input and output values of $D M U_{j}, j=1, \ldots, n$, respectively.

We will consider the maximum value in each component of the output.

For $D M U_{1}$ we have:

$\operatorname{Max} y_{11}=y_{11}^{*}, \quad \operatorname{Max} y_{21}=y_{21}^{*} \ldots \operatorname{Max} y_{s 1}=y_{s 1}^{*}$.

For $D M U_{2}$ we have:

$\operatorname{Max} y_{12}=y_{12}^{*}, \quad \operatorname{Max} y_{22}=y_{22}^{*} \ldots \operatorname{Max} y_{s 2}=y_{s 2}^{*}$.

For $D M U_{n}$ we have:

$\operatorname{Max} y_{1 n}=y_{1 n}^{*}, \quad \operatorname{Max} y_{2 n}=y_{2 n}^{*} \ldots \operatorname{Max} y_{s n}=y_{s n}^{*}$.

Now, we define set $F$ as follow:

$$
F=\left\{y_{r j}^{*}, \quad r=1, \ldots, s, \quad j=1, \ldots, n\right\} .
$$

A DMU in set $F$ has the highest amounts of $i$ th input component compared with other selected DMUs:

$$
\begin{aligned}
& \exists(t \in F) ; \quad \forall(j \in F) \Rightarrow x_{i t} \geq x_{i j}, \\
& x_{i t}=x_{i}^{*}, \quad i=1, \ldots, m .
\end{aligned}
$$

For example, in set $F, D M U_{t}$ has the highest amounts of first input component compared with the first input component of other DMUs:

$$
\exists(t \in F) ; \quad \forall(j \in F) \Rightarrow x_{1 t} \geq x_{1 j} ; \quad x_{1 t}=x_{1}^{*} .
$$

$D M U_{k}$ has the highest amounts of second input component compared with the second input component of other DMUs:

$$
\exists(k \in F) ; \quad \forall(j \in F) \Rightarrow x_{2 k} \geq x_{2 j} ; \quad x_{2 k}=x_{2}^{*},
$$

and so on.

Definition 1. We have congestion if at least there is one $x_{i p}>x_{i}^{*}(i=1,2, \ldots, m)$. The congestion in the $i$ th input of $D M U_{P}$ is:

$$
s_{i}^{c}=x_{i p}-x_{i}^{*}, \quad\left(x_{i p}>x_{i}^{*}\right) .
$$

For a better understanding, refer to Example 1.

To prove the accuracy of our method, we propose the following theorem.
Theorem 1. If each DMU has the maximum value in each component of the output, the DMU is weakly efficient and it is on the efficient frontier. Also by solving the output-oriented BCC model, we will have $\varphi^{*}=1$.

Proof. Assume for $D M U_{j}$ we have:

$$
\exists r \quad y_{r j}=y_{r}^{*} .
$$

Contrarily, suppose that in evaluating $D M U_{j}$ we have:

$$
\varphi^{*}>1 \Rightarrow\left(\begin{array}{c}
x_{j} \\
\varphi y_{j}
\end{array}\right) \epsilon P P S .
$$

Then there is another point on PPS (Production Possibility Set) that its $r$ th output is: $\varphi^{*} y_{r j}>y_{r j}=y_{r}^{*}$, which is a contradiction.

We can develop this theorem as follow. If each DMU has the maximum value in:

- One component of the output;

- Sum of two component of the output;

- Sum of tree component of the output;

- Sum of all components of the output;

then the DMU is weakly efficient, and it is on the effective boundary. By solving the output-oriented BCC model, we will have $\varphi^{*}=1$.

\section{Numerical example}

In this section, we apply our method to some numerical examples and compare the results of our method with the results of other methods.

\subsection{Example 1}

Assume that we have 8 DMUs with one input and one output as shown in Figure 1. Cooper et al. [8] and Noura et al. [10] solved this example through their models. Here, we apply our method to this example and compare the results in Table 1.

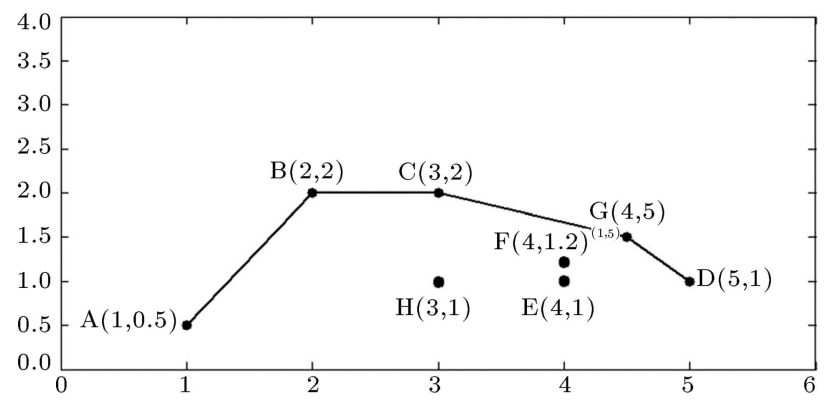

Figure 1. Numerical Example 1. Source: Brockett et al. [7] and Noura et al. [10]. 
Table 1. Results of Example 1.

\begin{tabular}{cccc}
\hline & \multicolumn{3}{c}{ Congestion } \\
\cline { 2 - 4 } DMU & $\begin{array}{c}\text { Cooper et al. [8] } \\
\text { approach }\end{array}$ & $\begin{array}{c}\text { Noura et al. [10] } \\
\text { approach }\end{array}$ & $\begin{array}{c}\text { Our new } \\
\text { method }\end{array}$ \\
\hline A & 0 & 0 & 0 \\
B & 0 & 0 & 0 \\
C & 0 & 0 & 0 \\
D & 2 & 2 & 2 \\
E & 1 & 1 & 1 \\
F & 1 & 1 & 1 \\
G & 1.5 & 1.5 & 1.5 \\
H & 0 & 0 & 0 \\
\hline
\end{tabular}

Table 2. DMUs' data. Source: Khoveyni et al. [17].

\begin{tabular}{cccccccccccccccc}
\hline DMU & $\mathbf{A}$ & $\mathbf{B}$ & $\mathbf{C}$ & $\mathbf{D}$ & $\mathbf{E}$ & $\mathbf{F}$ & $\mathbf{G}$ & $\mathbf{H}$ & $\mathbf{I}$ & $\mathbf{J}$ & $\mathbf{K}$ & $\mathbf{L}$ & $\mathbf{M}$ & $\mathbf{N}$ & $\mathbf{O}$ \\
\hline Input 1 & -1 & -3 & 0 & -2 & -2 & 2 & 4 & -2 & -2 & 4 & 3 & -2 & 3 & 2 & 3 \\
Input 2 & -3 & -1 & -2 & 0 & 2 & -2 & -2 & 4 & 2 & 4 & -2 & 3 & 3 & 1 & 3 \\
Output & -1 & -1 & 1 & 1 & 1 & 1 & 0 & 0 & 1 & 0 & 0.5 & 0.5 & 0.5 & -2 & -3 \\
\hline
\end{tabular}

$D M U_{B}$ and $D M U_{C}$ have the maximum output value. Set $F$ is:

$$
F=\left\{y_{B}=y_{C}=2\right\} \text {. }
$$

$D M U_{C}$ in set $F$ has the highest amounts of input compared with $D M U_{B}$. So, we have:

$$
x^{*}=x_{C}=3 \text {. }
$$

The congestion in the input of $D M U_{D}$ is:

$$
x_{D}^{C}=x_{D}-x^{*}=5-3=2 .
$$

The congestion in the input of $D M U_{E}$ is:

$$
x_{E}^{C}=x_{E}-x^{*}=4-3=1 .
$$

The congestion in the input of $D M U_{F}$ is:

$$
x_{F}^{C}=x_{F}-x^{*}=4-3=1 .
$$

The congestion in the input of $D M U_{G}$ is:

$$
x_{G}^{C}=x_{G}-x^{*}=4.5-3=1.5 .
$$

In the method proposed by Cooper et al. [8], the model is solved through three steps (Model (1)); This implies that we must solve three models to measure the congestion. According to the method proposed by Noura et al. [10], we must solve two models (outputoriented BCC (Model (2)) then we have to do the computations (Models (3) and (4)). As you can see, in the presented method, there is no need to solve a model and, as shown in Table 1 , the results of the three methods are the same.

\subsection{Example 2}

Assume that we have 15 DMUs with two inputs and one output as shown in Table 2 .

Khoveyni et al. [17] solved this example through their models. Here, we apply our method to this example and compare the results in Table 3.

$$
\begin{aligned}
& F=\left\{y_{C}=y_{D}=y_{E}=y_{F}=y_{I}=1\right\}, \\
& x_{1}^{*}=x_{1 F}=2, \quad x_{2}^{*}=x_{2 E}=x_{2 I}=2, \\
& x_{G}^{C}=x_{1 G}-x_{1}^{*}=4-2=2, \\
& x_{H}^{C}=x_{2 H}-x_{2}^{*}=4-2=2, \\
& x_{J}^{C}=\left\{\begin{array}{l}
x_{1 J}-x_{1}^{*}=4-2=2 \\
x_{2 J}-x_{2}^{*}=4-2=2
\end{array}\right. \\
& x_{K}^{C}=x_{1 K}-x_{1}^{*}=3-2=1
\end{aligned}
$$

Table 3. Results of Example 2.

\begin{tabular}{ccc}
\hline & \multicolumn{2}{c}{ Congestion } \\
\cline { 2 - 3 } DMU & $\begin{array}{c}\text { Khoveyni et al. [17] } \\
\text { approach }\end{array}$ & $\begin{array}{c}\text { Our new } \\
\text { method }\end{array}$ \\
\hline $\mathbf{G}$ & Weak congestion & Weak congestion \\
$\mathbf{H}$ & Weak congestion & Weak congestion \\
$\mathbf{J}$ & Strong congestion & Strong congestion \\
$\mathbf{K}$ & Weak congestion & Weak congestion \\
$\mathbf{L}$ & Weak congestion & Weak congestion \\
$\mathbf{M}$ & Strong congestion & Strong congestion \\
$\mathbf{O}$ & Inefficient & Strong congestion \\
\hline
\end{tabular}




$$
\begin{aligned}
& x_{L}^{C}=x_{2 L}-x_{2}^{*}=3-2=1 \\
& x_{M}^{C}=\left\{\begin{array}{l}
x_{1 M}-x_{1}^{*}=3-2=1 \\
x_{2 M}-x_{2}^{*}=3-2=1
\end{array}\right. \\
& x_{O}^{C}=\left\{\begin{array}{l}
x_{1 O}-x_{1}^{*}=3-2=1 \\
x_{2 O}-x_{2}^{*}=3-2=1
\end{array}\right.
\end{aligned}
$$

According to the method proposed by Khoveyni et al. [17] method must solve at least three models ((5), $(6),(7))$ must be solved to find a DMU with weak or strong congestion efficiency. As you can see here, we measure the congestion in each input and distinguish between weak or strong congestion for all DMUs, not just for those with high efficiency, without the need to solve the model.

Assume that we had 1500 DMUs instead of 15 DMUs. Using Khoveyni et al. [17] methods means that solving lots of models with immense data, but our purposed method has simple calculating.

\subsection{Example 3}

Assume that we have 8 DMUs with one input and one output as shown in Table 4. Abbasi et al. [13] solved this example through their models. Here, we apply our method to this example and compare the results in Table 5 .

$$
\begin{aligned}
& F=\left\{y_{D}=y_{E}=4\right\}, \quad x^{*}=x_{E}=7, \\
& x_{F}^{C}=x_{F}-x^{*}=8-7=1, \\
& x_{G}^{C}=x_{G}-x^{*}=8-7=1, \\
& x_{H}^{C}=x_{H}-x^{*}=9-7=2 .
\end{aligned}
$$

In the method presented by Abbasi et al. [13], two mixed-integer programming models $((8)$ and $(9))$ must be solved to measure the congestion. As you can see, in our method there is no need to solve a model and as shown in Table 5, the results of the two methods are the same.

Table 4. DMUs' data. Source: Abbasi et al. [13].

\begin{tabular}{ccccccccc}
\hline DMU & A & B & C & D & E & F & G & H \\
\hline Input & 2 & 3 & 5 & 6 & 7 & 8 & 8 & 9 \\
Output & 1 & 3 & 2 & 4 & 4 & 3 & 1 & 2 \\
\hline
\end{tabular}

Table 5. Results of Example 3.

\begin{tabular}{ccc}
\hline & \multicolumn{2}{c}{ Congestion } \\
\cline { 2 - 3 } DMU & $\begin{array}{c}\text { Abbasi et al. [13] } \\
\text { approach }\end{array}$ & $\begin{array}{c}\text { Our new } \\
\text { method }\end{array}$ \\
\hline G & 1 & 1 \\
F & 1 & 1 \\
H & 2 & 2 \\
\hline
\end{tabular}

\section{Conclusion}

In this paper, we proposed a new method for measuring the congestion without solving the model. It can be used for different production possibility set (different technology) such as $T_{N e w}$ and FDH and different data such as negative data and integer data. In addition, we can distinguish between strong congestion and weak congestion of the Decision-Making Unit (DMU). Also, each DMU has both efficient and inefficient congestion, and we can measure them through this method.

We applied our method in three different fields and the results are shown in the tables. As we discussed in Section 4, each case has a separate model and a separate calculation for the methods presented in the past. For example, for the Free Disposal Hull (FDH) production possibility set, two mixed-integer programming models must be used or for negative data, we must use three complex models. Suppose we have thousands of DMUs with a large number of inputs and outputs; these models require a lot of time and complex calculations. But our method is not complicated, and we got the answer without wasting time. As you saw in Section 4, our method is very simple compared to other methods, and we get the answer too fast without solving the model.

To provide the ground for further studies, we can extend our method for fuzzy and interval data. Because there is no need to solve a model in our method; it seems good to use our method to measure the congestion of these data.

\section{References}

1. Charnes, A., Cooper W.W., and Rhodes, E. "Measuring the efficiency of decision-making units", European Journal of Operational Research, 2, pp. 429-444 (1978).

2. Banker, R.D., Charnes, A., and Coopper, W.W. "Some models for estimating technical and scale inefficiencies in data envelopment analysis", Journal of Management Science, 30, pp. 1078-1092 (1984).

3. Cooper, W.W., Seiford, L.M., and Zhu, J. "A unified additive model approach for evaluating inefficiency and congestion whit associated measures in DEA", SocioEconomic Planning Sciences, 34, pp. 1-25 (2000).

4. Cooper, W.W., Deng, H., Seiford, L.M., and Zhu, J. "Congestion: its identification and management with DEA", In: cooper WW, Seiford LM, Zhu J, editors, Handbook of data envelopment analysis, Boston: Kluwer; p. 177e201 (2004).

5. Färe, R. and Grosskopf, S. "Measuring congestion in production", Journal of Economics, 43, p. $257 \mathrm{e} 71$ (1983).

6. Färe, R. and Grosskopf, S. "When can slacks be used to identify congestion. An answer to W. W. Cooper, L. 
Seiford, J. Zhu", Socio-Economic Planning Sciences, 35, p. 1e1 (2001).

7. Brockett, P.L., Cooper, W.W., Shin, H.C., and Wang, $\mathrm{Y}$. "Inefficiency and congestion in Chinese production before and after the 1978 economic reforms", SocioEconomic Planning Sciences, 32, pp. 1-20 (1998).

8. Cooper, W.W., Deng, H., Huang, Z.M., and Li, S.X. "A one-model approach to congestion in data envelopment analysis", Socio-Economic Planning Sciences, 36, pp. 231-8 (2002).

9. Khodabakhshi, M. "A one-model approach based on relaxed combinations of inputs for evaluating input congestion in DEA", Journal of Computational and Applied Mathematics, 230, pp. 443-450 (2009).

10. Noura, A.A., Hosseinzadeh Lotfi, F., Jahanshahloo, G.R., Fanati Rashidi, S., and Parker Barnett, R. "A new method for measuring congestion in data envelopment analysis", Socio-Economic Planning Sciences, 44, pp. 240-246 (2010).

11. Zare-Haghighi, H., Rostamy-Malkhalifeh, M., and Jahanshahloo, G.R. "Measurement of congestion in the simultaneous presence of desirable and undesirable outputs", Journal of Applied Mathematics, 2014, Article ID: 512157, 9 pages (2014). https://doi.org/10.1155/2014/512157.

12. Mollaeian, E. and Rostamy-Malkhalifeh, M. "Detect and eliminate congestion of the intermediate products in supply chain", International Journal of Data Envelopment Analysis, 2(2), Article ID IJDEA-00225, 7 pages (2014).

13. Abbasi, M., Jahanshahloo, G.R., Rostamy-Malkhlifeh, M., and Hosseinzadeh Lotfi, F. "Estimation of congestion in free disposal hull models using data envelopment analysis", The Scientific World Journal, 2014, Article ID: 427673, 8 pages (2014). https://doi.org/10.1155/2014/427673

14. Sueyoshi, T. and Goto, M. "Undesirable congestion under natural disposability and desirable congestion under managerial disposability in U.S. electric power industry measured by DEA environmental assessment", Energy Economics, 55, pp. 173-188 (2016).

15. Sueyoshi, T. and Goto, M. "Returns to damage under undesirable congestion and damages to return under desirable congestion measured by DEA environmental assessment with multiplier restriction: Economic and energy planning for social sustainability in China", Energy Economics, 56, pp. 288-309 (2016).

16. Ebrahimzade Adimi, M., Rostamy-Malkhalifeh, M., Hosseinzadeh Lotfi, F., and Mehrjoo, R. "A new linear method to find the congestion hyperplane in DEA", Mathematical Sciences, 13, pp. 43-52 (2019).
17. Khoveyni, M., Eslamib, R., and Yang, G.L. "Negative data in DEA: Recognizing congestion and specifying the least and the most congested decision making units", Computers \& Operations Research, 79, pp. 3948 (2017).

18. Wang, Q., Wan, J., and Yuan, Y. "Locality constraint distance metric learning for traffic congestion detection", Pattern Recognition, 75, pp. 272-281 (2018).

19. Sole-Ribalta, A., Arenas, A., and Gomez, S. "Effect of shortest path multiplicity on congestion of multiplex networks", New Journal of Physics, 21, Open access (2019).

20. Zhou, D.Q., Meng, F.Y., Bai, Y., and Cai, S.Q. "Energy efficiency and congestion assessment with energy mix effect: The case of APEC countries", Journal of Cleaner Production, 142, pp. 819-828 (2017).

21. Zhou, P., Wu, F., and Zhou, D.Q. "Total-factor energy efficiency with congestion", Annals of Operations Research, 255, pp. 241-256 (2017).

22. Hu, J.L., Chang, M.C., and Tsay, H.W. "The congestion total-factor energy efficiency of regions in Taiwan", Energy Policy, 110, pp. 710-718 (2017).

\section{Biographies}

Sarah Navidi is a PhD student of Operations Research at the Science and Research Branch, Islamic Azad University, Tehran, Iran. She received her BSc and MSc degree in Applied Mathematics from Islamic Azad University, Central Tehran Branch, Iran. Her research interests are Applied Mathematics, Operation Research, Data Envelopment Analysis (DEA).

Mohsen Rostamy-Malkhalifeh received his $\mathrm{PhD}$ degree in Applied Mathematics from Science and Research Branch, Islamic Azad University, Tehran, Iran. $\mathrm{He}$ is currently an Associate Professor of Operation Research at the Science and Research Branch, Islamic Azad University. His research interests are applied mathematics, operational research, Data Envelopment Analysis (DEA).

Farhad Hosseinzadeh Lotfi received his $\mathrm{PhD}$ degree in Applied Mathematics from Science and Research Branch, Islamic Azad University, Tehran, Iran. He is currently a Professor of Operation Research at the Science and Research Branch, Islamic Azad University. His research interests are mathematics, operation research, Data Envelopment Analysis (DEA), and efficiency. 